\title{
Effects of Self-presentation and Social Media Use in Attainment of Beauty Ideals
}

\author{
Rebecca K Britt \\ Correspondence: Rebecca K. Britt, Department of Journalism and Mass Communication, South Dakota State \\ University, Yeager Hall 211, Brookings, SD, 57007, Tel: 440.221.4468, USA
}

Received: February 28, 2015 Accepted: March 20, 2015 Online Published: May 11, 2015

doi:10.11114/smc.v3i1.705

URL: http://dx.doi.org/10.11114/smc.v3i1.705

\begin{abstract}
The Hyperpersonal Model and the Theory of Planned Behavior were integrated to explore self-esteem and use of beauty-related content on social media sites. A multiple regression model tested the relationship between beauty related social media use, enjoyment and self-esteem. Results indicate that participants who reported frequent use of beauty-based social media contents had higher self-esteem and greater engagement with online content. Implications and suggestions for research lines are offered.
\end{abstract}

Keywords: hyperpersonal model, theory of planned behavior, social media use, self-presentation, self-esteem

\section{Introduction}

\subsection{Introduction}

Self-presentation has long been examined in scholarly research, from its earliest origins as an ideological construct (Goffman, 1959; Jones \& Pittman, 1982) to a psychological trait frequently investigated in computer-mediated communication (CMC) scholarship (Jiang, Bazarova, \& Hancock, 2011; Pontari \& Schlenker, 2006). More specifically, prevailing beauty ideals from the media standardize an objectified view of one's own self-presentation, resulting in increased monitoring of appearance (Frederickson \& Roberts, 1997; Moradi \& Huang, 2008). For instance, self-presentation ideals are constantly visible in popular mass media, although increased exposure to sexually objectifying ideals is expected to result in both physical and mental health risks (Aubrey, 2006). Traditional and new media have been found to regularly focus on women's appearances by encouraging them to change the way they look, while ignoring their personalities (Parker, 2002). Women are typically expected to follow prevalent beauty ideals from mass media. As a result, beauty standards guide the formation of their own self-identity and may heighten self-monitoring of their appearance.

As social media increase in popularity, women in particular are encouraged to change their appearance to be more attractive online by companies that create instigate beauty ideals- namely, cosmetics companies. Distributors of mass media messages, such as cosmetics companies, have largely adopted the use of social media sites (SMSs), which have proved to be a successful marketing strategy. Via SMSs, everyday individuals make use of Facebook groups, blogs, YouTube channels, and other communication channels. As opposed to celebrity endorsements in traditional mass media, everyday individuals have emerged online as relatable personas (Burke, 1959; Cooper, 2004) encourage the use of these products, promote the items, and share before-and-after images. Building on the burgeouing ways in which self-presentation manifests through social media use, the current study builds upon research using the Hyperpersonal model (Walther, 1996) and the Theory of Planned Behavior (TPB; Ajzen, 1991) as a cursory exploration of self-esteem and use of beauty-related social media web sites. The contribution of the study is that it introduces the implications of self-presentation based on beauty ideals as a construct for exploration. A secondary contribution is in the impact of media standardizations of one's own self-presentation, which scholars have argued warrants more attention (Tiggerman, 2010). The implications of self-presentation based on social media sites that encourage the use of changing one's appearance may increase vulnerability, increased self-objectification, and decreased self-esteem (Frederickson \& Roberts, 1997).

\subsection{Importance of the Problem}

This research aims to contribute to a growing body of communication and theory-based scholarship with two key goals in mind (1) to assess and use Walther's (1996) hyperpersonal model as a framework for understanding and making sense of participatory behaviors on social media sites (SMSs); (2) to further this framework by using the theory of planned 
behavior (TPB) (Ajzen, 1991) in conjunction, due to its clear construction of variables that contribute towards attitudes, normative, and perceived control beliefs that contribute towards behavioral intention. Finally, we wish to contribute towards a new research program that is rooted in the movement of beauty as a popularized content online - which we describe, for the purposes of this study, as beauty-related social media (BRSM). Ultimately, the opportunity afforded by the tremendous growth in new media offers an unparalleled opportunity to open the floor for collaboration and discussion of this research, and to contribute towards a meaningful conversation of growing scholarship today — and how we might further meaningful scholarship that seeks to explore new media and constructs of the self and well-being.

\subsection{The Hyperpersonal Model}

The Hyperpersonal model (Walther, 1996) suggests that online interactions are empowered by technological enhancements that construct strategic communication. Asynchronicity, or the time lag in-between message construction and dispatchment, allows for communicators to carefully self-select in presentation strategies. For instance, a communicator enabling a beauty-ideal via social media can carefully strategize and edit his or her self-presentation, which allows for a nuanced selective and optimized presentation of themselves to the audience. Walther (1996) argues that hyperpersonal communication is "more socially desirable than we tend to experience in parallel [face-to-face] FTF interaction" (p.17). According to Walther, hyperpersonal communication takes media attributes, social phenomena and social processes to exceed traditional FTF communication.

Taken together, the affordances of asynchronicity and technical mediation form selective self-presentation, which results in an optimal version of face-to-face presentation (Walther, 1996). Selective self-presentation includes strategizing to the extent of emphasizing positive qualities and omitting negative ones, contextualizing content by framing it in a flattering way (Ellison, Heino, \& Gibbs, 2006; Toma \& Carlson, 2015). As a result, the receiver of these self-selected messages tends to over interpret the sender's personal qualities and content of their messages, as opposed to FTF content (Walther, 1996). For instance, the beauty tutorials that YouTube user Michelle Phan posts are edited and simplified, likely to appeal to a wide audience. The editing practice may lead to receivers perceiving that the ease associated with putting on a cosmetic to alter one's appearance is a norm that is easy to accomplish (e.g., Ajzen, 1991). Furthermore, the popularity of the videos perpetrate a norm that suggests self-presentation online must be deliberate and that one must always put their best face forward (Morry \& Statska, 2001; Grabe \& Hyde, 2009), despite the fact the videos themselves are very likely carefully edited. Similarly, people who share frequent beauty purchases on social media sites like Facebook and Twitter may give the impression that it is normal to frequently purchase expensive cosmetics and use on a full spectrum of those products on a daily basis. Instances of communication on these channels represent selective self-presentation (Walther, 1996) via overemphasized, carefully constructed messages.

Many studies on self-presentation have examined the role of body surveillance to better understand how the mass media triggers self-objectification (Grabe \& Hyde, 2009; Moradi, 2010; Morry \& Statska, 2001). As the shift from mass to social media occurs, over the past several years, there has been an influx of social media that perpetrate beauty ideals that further exemplify the Hyperpersonal model. Some of the most popular YouTube channels in the years 2013-2014 are beauty channels, where the contents review products and advertise ways to alter imperfections and change one's appearance. Many of these videos, blog posts, and other social media posts are sponsored by cosmetics companies, although this is often only apparent by viewing the fine print below a video itself. For instance, on YouTube, the video channel for beauty entrepreneur Michelle Phan has over 5 million subscribers and approximately 4,300 views per day (VidStats, 2014). Similarly, Elle and Blair Fowler have beauty channels with over 250 million views (Fowler, 2014a; Fowler, 2014b). These individuals encourage responses from viewers to share photos or videos of themselves using the products and to share their thoughts. In some cases, these individuals are sent products from companies for review. By positively reviewing the product in their videos, these individuals can persuade their viewers to purchase the products, sometimes at a discount offered by the company for viewers of that particular channel.

According to the Hyperpersonal model, the instigators of popular beauty-related social media sites enact in selective self-presentation, while the viewers of this content (message receivers) have limited access to nonverbal attributes and other cognitive resources, which lead them to form more stereotypical impressions of the sender of these messages (Walther \& Parks, 2002). The senders of CMC messages only give selective information about themselves, unconstrained by FTF cues and burgeoned by the asynchronicity of technology. As the Hyperpersonal model (Walther, 1996) proposes, people put their best foot forward in online interactions by being selective in their self-presentation. The photos that people post of themselves wearing products on a company Facebook page, for instance, very likely deliberately share attractive photos rather than ones they deem less attractive ones, likely omitting less desirable features (Hancock \& Toma, 2009).

Moreover, while consumer research on beauty products has found that online promotion via web sites and social media has increased sales (e.g., Jawahar \& Tamizhjyoti, 2013; De Vries, Gensler, \& Leeflang, 2012; Kharim, 2011; Guthrie \& 
Kim, 2009), there is little existing research on the social-psychological effects. Participants on social media web sites for beauty brands are encouraged to post responses to questions that the companies pose about how individuals make use their products, which help to promote the products in a strategic manner. Selective self-presentation tactics, though, are not made spontaneously, nor are they sporadic. Rather, they may result from a reasoned action process (e.g., Ajzen, 1991; Fishbein \& Ajzen, 1975). Scholarship argues that self-presentation stems from several components, including selective self-presentation in online contexts (e.g., Ellison, Heino, \& Gibbs, 2006; Walther, 1996) but also normative beliefs based on the influence of other individuals, attitudes, perceived behavioral control, which then influence actual behavior. For instance, beauty ideals popularized in mass and social media may influence someone, but additional variables influence actual behavior. As social media grow at an unprecedented rate, the concept of self-presentation is one that can be further examined today through the use of SMSs. Scholarly evidence shows that primarily women who use cosmetics tend to improve in their self-image and attitude towards socializing with others, and tend to have a more positive outlook (Graham \& Kligman, 1984, 1985), although this may be in part due to mass media effects. Moreover, women have also been found to exhibit an awareness of self-presentation by wearing more cosmetics when anticipating meeting an attractive person for the first time (Regan, 2011). These findings are consistent with other studies that tend to argue that people make judgments on generalized stereotypes (Jacob, Guégen, Boulbry, \& Ardiccioni, 2010; Adams \& Huston, 1975). Given these findings, while the Hyperpersonal model offers an explanation for CMC, the TPB offers a model of explanation for behavioral intent via CMC channels.

\subsection{Self-perception and self-esteem}

The concept of self-presentation in the current study is constructed as a variable associated with selective construction, akin to impression management (Leary \& Kowalski, 1990). Impression management proposes that construction of the self is determined by the impression one tries to make and chooses how they go about doing it. Papacharissi (2002) describes the web as being a place where authors can "stage an online performance through which the individual's personality or aspects of it are revealed" (p.654).

In past research on self-esteem and online interaction, individuals with high self-esteem are more likely to use online dating services (Kim, Kwong, \& Lee, 2009), communicate with friends (Steinfield, Ellison \& Lampe, 2009) and generally lead more positive lives. The use of social media has been associated with higher self-esteem (Back et al., 2010), as well as fulfilling a need of self-presentation (Gosling, Gaddis, \& Vazire, 2007). We may expect, then, that there may be a positive relationship between use of beauty-related social media and self-esteem. However, scholarship has also found that social media use is also associated with only momentary increases of self-esteem, or with ties that are particularly close (Wilcox \& Stephen, 2013). Furthermore, individuals with lower self-esteem have been more likely to have problematic Internet use (Kim \& Davis, 2009), and tendency to require help from others, compared to those with high-self esteem, who seek more independence (Leary et al., 2009). Given the mix of previous findings, the following research question is posed to first explore the possible relationship of beauty-realted social media use and self-esteem:

RQ1: Do users of beauty-related social media sites report higher or lower self-esteem?

\subsection{The Theory of Planned Behavior}

The premise of the TPB is that behavioral decisions are made as a result of numerous indirect influences, by attitudes, subjective norms, and perceptions of behavioral control (Ajzen, 1991; Fishbein \& Ajzen, 1975). Specifically, TPB proposes that attitudes are the evaluation of the target behavior (in this case, engagement with beauty-related content); subjective norms are perceived social pressures (perception of the normalization of what other individuals are engaging in with beauty related social media), and perceived behavioral control is the perception of control over the behavior (perceived capacity to engage in participation with beauty related social media content). A further explanation of the key variables in the TPB framework is offered below.

Attitudinal beliefs. Attitudes are either positive or negative evaluations of a person's perception towards enacting in a given behavior. Generally, attitudes are thought of as the degree to which performing the behavior is valued as positive or negative. SMSs like Facebook particularly encourage sharing attitudinal beliefs with features such as the 'like' button, wall posts, and participating in polls and surveys.

Subjective norms. Subjective norms are considered a social influence factor that can alter an individual's perception. Typical normative beliefs are whether or not referent groups (e.g., friends, family, coworkers) important to a person think that they should behave in a certain way (spending time online, wearing makeup). Subjective norms are typically articulated as injunctive norms because they refer to typical rules and beliefs that constitute approval or disapproval in behavior.

Perceived behavioral control (PBC). PBC is the measure of the perception of ability to complete a given task (i.e., tape, edit, and upload a YouTube video). PBC has two parts: perceived capacity and perceived autonomy (Yzer, 2007), which 
are, respectively, the degree to which one believes they can perform a behavior (Ajzen, 1991); and the degree to which they believe they have control over that behavior.

In TPB research, self-presentation has been used as a predictor of behavioral intent, independent of normative beliefs (Fedaku \& Kraft, 2001; Sparks \& Guthrie, 1998). Self-presentation has generally been supported as a predictor in exploring the role of identity-related influences (Thorbjornsen, Pedersen, \& Nysveen, 2007). For instance, self-presentation and self-esteem have largely been explored in planned behavior-based health interventions (Wang, 2009). For instance, low self-esteem individuals are more likely than high self-esteem individuals to maintain a positive self-image (Wang, 2009), although this is not always the case (Gosling, Gaddis, \& Vazire, 2007), since some individuals have a greater need to be value-expressive (e.g., Herek, 2000).

As a result of the factors posed by the Hyperpersonal model and TPB, the overall intention to engage in an online behavior is summed by the above variables. Not all factors necessarily work in tandem to explain behavior, though they sometimes do. In exploring the influence of beauty ideals perpetuated online, the influence of self-presentation and TPB variables may impact self-esteem. Prior research indicates that CMC becomes more personal over time because interactions increase, and perceptions of fellow communicators are positively skewed (Walther, 1996). This is interesting when we think of beauty related social media, because beauty products change over time, and so does the coverage of products, tutorials and ideas that people share. We might expect, then, that CMC users of beauty-related social media to be more likely to participate in such media in the future. Past research has found strong support that past behavior influences future intention (Ajzen, 1991). As a result of these variables, the second research question is offered:

RQ2: Do users of beauty social media sites show greater intention (as a result of attitude, normative, and PBC-based beliefs) to participate in beauty-related social media in the future?

\subsection{Research Questions}

Prior research indicates that $\mathrm{CMC}$ becomes more personal over time because interactions increase, and perceptions of fellow communicators are positively skewed (Walther, 1996). This is interesting when we think of beauty related social media, because beauty products change over time, and so does the coverage of products, tutorials and ideas that people share. We might expect, then, that users of this content would be more likely to participate in beauty-related social media the future. Past research has found strong support that past behavior influences future intention (Ajzen, 1991), but coming from the perspective of hyperpersonal media, we still question this because CMC change over time quickly. As such, the following two research questions are reiterated:

RQ1: Do users of beauty-related social media sites report higher or lower self-esteem?

RQ2: Do users of beauty social media sites show greater intention (as a result of attitude, normative, and PBC-based beliefs) to participate in beauty-related social media in the future?

\section{Method}

There are many methods used to study online interaction. Survey research can capture what people do online and why they say what it is they do online, such as the Pew Internet and American Life Project (http://pewinternet.org), as well as prolific research (e.g. Kahn, Ratan, \& Williams, 2014; Katz \& Rice, 2002; Smith, 1997). As such, the current study was designed to address a preliminary set of questions.

The study was conducted via a Qualtrics survey used to assess participants' interest and use of beauty-related online social media. First, a set of demographic questions were asked, followed by Rosenberg's (1965) self-esteem scale. Following this, participants were asked about their enjoyment of beauty-related social media content, and were given examples of this (e.g., social media sites, blogs, videos). Participants were asked to elaborate on their response in an open-ended question if they opted. Upon completion of these questions, participants were finished with the survey and thanked for their time.

\subsection{Procedures and Participants}

Upon Institutional Review Board approval, participants were recruited at a large, Midwestern university in the United States. The survey was distributed via an online recruitment system to students, with a brief description of the purpose of the study. Participants who were students were given the option of taking the survey for extra credit (up to instructor's discretion) in a class of their choice. Out of 463 respondents, a total of 461 usable responses were included for the survey. Out of the given responses, $68.3 \%$ were female and $31.7 \%$ were male. Participants reported their ethnicity as Caucasian (85.5\%), African American (10.0\%), Asian-American (2.5\%), and Hispanic/Latino (2.5\%), with 5 missing values. Most participants were between the ages of 18-25 (99.1\%), with several between the ages of 26-34 (0.5\%) and 35-54 (0.5\%). Out of the participants, the question that asked about enjoyment resulted in responses where over half of all participants reported enjoying beauty related social media $(55.3 \%)$, with the majority of those users being female $(96.5 \%)$. 


\subsection{Measures}

Enjoyment of beauty related social media. Participants were asked a baseline question that inquired if they enjoyed beauty related social media on a five point Likert scale. The question stated, "I enjoy beauty-related social media online (for instance, videos on YouTube, tutorials on blogs and online, etc." (Cronbach's alpha $=.91$ ).

Self-esteem. Self-esteem was measured using the Rosenberg self-esteem scale (RSES; Rosenberg, 1965), a widely used self-report measure used in social scientific research. It is a ten-item Likert scale with items answered on a 4-point scale from "Strongly Agree" to "Strongly Disagree" with five positive and five negative statements. Examples of items include "On the whole, I am satisfied with myself," and "At time I think I am no good at all." Scores for the items range from 10 to 40, with higher scores indicating higher self-esteem. Internal consistency for reasonable levels are between .72 and .88 (Byrne, 1996). The Cronbach's alpha for the RSES was .85.

Behavior, intent, attitudes, subjective norms, and perceived behavioral control were all measured using Fishbein \& Ajzen's (2010) TPB questionnaire, which is designed to allow researchers to insert his or her construct(s) of interest. In accordance with Fishbein \& Ajzen's guidelines, the main construct of interest, HPV vaccination activity was inserted into each of the 21 items in the scale. Each subscale, in direct accordance with the questionnaire, is described in detail below.

Intent. Intent to was measured by the average of three items on a seven-point scale ( $\mathrm{M}=4.38, S D=1.25)$. The scale showed high internal consistency (Cronbach's alpha=.92).

Attitudes. Attitudes were measured by the mean of an eight-item semantic differential (e.g., beneficial/harmful, good/bad, worthless/valuable, etc.) on a seven-point scale $(\mathrm{M}=4.39, S D=1.67)$. These items showed strong reliability (Cronbach's alpha=.93).

Subjective Norms. Perceptions of normative influences over interacting with beauty related social media (e.g., "Most people who are important to me think that I should participate in beauty blogs or web sites," "Many women like me plan on participating in beauty blogs.") on seven-point scales $(M=3.90, S D=2.46)$. The scale showed good internal consistency (Cronbach's alpha=.95).

Perceived Behavioral Control. The average of five items was used to assess perceived behavioral control using seven-point scales $(\mathrm{M}=4.35, S D=1.52)$. Items included, "If I wanted to, I could engage in a cosmetics Facebook or Twitter page in the next year," and "It is mostly up to me if I participate in a cosmetics-based YouTube group in the next year." The items showed good reliability (Cronbach's alpha=.91).

Multiple hierarchical regression analyses were used to address each research question. Variables were mean-centered to reduce errors of multicollinearity and product terms were created to represent all two-way interactions.

\section{Results}

To address RQ1, an interaction term was created (Attitudes x Perceived Behavioral Control). This investigates a moderating effect on perceived behavioral control, which current research supports (e.g., Britt \& Hatten, 2013; Dillard \& Spear, 2010). Dillard \& Spear (2010) argued that as researchers continue to study TPB, exploring the relationship of attitudes and $\mathrm{PBC}$ in a more nuanced fashion provides a more in-depth understanding of the way the variables interact (Hayes, 2009). Previous studies have already proven this (Ajzen, Albarricin, \& Hornik, 2007; Dillard \& Spear, 2010).

RQ1 asked, "Do users of beauty related social media report higher or lower self-esteem?" A hierarchical multiple regression was performed. The control variables (Gender, Age) were entered in Step 1 and were not statistically significant with users of beauty-related social media or with self-esteem. Step 2 included attitudes towards beauty related social media, $F(5)=.253, p=.003, R^{2}=.076$. In Step 3, PBC towards beauty related social media was entered in to the model, where $\mathrm{r}^{2}=.08, \mathrm{p}<.0001$. In Step 4, the interaction term of attitudes $\mathrm{x}$ perceived behavioral control was added, $\mathrm{r}^{2}=.067, \mathrm{p}<.0001$. Table 1 shows the results of the analysis in detail. Based on our results, the data does suggest that users or beauty related social media reported higher self-esteem, though that is extrapolated upon in the discussion section. We speculate these results as the first step to gaining insight into users, rather than suggesting that this fully addresses the question at hand. 
Table 1. Model of beauty-related social media use self-esteem

\begin{tabular}{llllllllll}
\hline & $\mathrm{B}$ & $\mathrm{SE}$ & $\beta$ & $\mathrm{t}$ & $\mathrm{S}$ Sig. & \multicolumn{2}{l}{ Zero-order } & Partial & Part \\
\hline Constant & 4.72 & 0.48 & - & 9.79 & $.00^{* *}$ & - & - & - \\
Attitudes towards BRSM & 1.03 & 0.06 & 0.85 & 16.1 & $.00^{* * *}$ & 0.81 & 0.81 & 0.77 \\
PBC towards BRSM & 0.08 & 0.04 & 0.87 & 1.75 & $.000^{* * *}$ & 0.15 & 0.14 & 0.83 \\
ATTxPBC & 0.05 & 0.06 & 0.79 & 0.79 & $.00^{* *}$ & 0.64 & 0.64 & 0.38 \\
\hline
\end{tabular}

Note. $* * * p<.0001 ; * * p<.001$

RQ2 asked if users of beauty-related social media intend to participate beauty media in the future. A simple linear regression was run to address the question, with intention to participate in beauty related social media as the predictor criterion. A significant relationship was found, $\mathrm{r}^{2}=.722, p<.0001$, with Table 2 shows the full results from the regression.

Table 2. Model of beauty-related social media use and intent

\begin{tabular}{llllllllll}
\hline & B & SE & $\beta$ & $\mathrm{t}$ & Sig. & Zero-order & Partial & Part \\
\hline Constant & 0.380 & 0.41 & - & 0.92 & $.00^{* *}$ & - & - & - \\
BRSM & 0.081 & 0.06 & 0.07 & 1.23 & $.00^{* *}$ & 0.83 & 0.60 & 0.40
\end{tabular}

Note. $* * p<.001$

In this instance, we feel that the answer to RQ2 makes sense, given that past behaviors (e.g., Ajzen \& Sheikh, 2013; Ajzen, 1991) tend to influence future behaviors, so the strong relationship that holds tells us that the model is a good fit in addressing the behaviors of users of beauty related social media.

\section{Discussion}

The purpose of the current study was to investigate the role of self-presentation via the Hyperpersonal model (Walther, 1996) and investigate a very early integration with the Theory of Planned Behavior (Ajzen, 1991; Fishbein \& Ajzen, 1975). As beauty-related social media content has increased in popularity, the influence of technological affordances (Norman, 2002) on self-presentation and resulting self-esteem are apparent (Toma, 2013). Self-presentation can have a positive effect on self-esteem (Wilcox \& Stephen, 2013; Valkenburg et al., 2006), but it has been long argued that the perpetual influences of beauty ideals negatively influence self-esteem (Dittmar, 2009; Jacob, Guégen, Boulbry, \& Ardiccioni, 2010).

The present study offers two findings. First, the relationship between enjoyment of beauty related social media and self-esteem indicates a need for qualitative investigation that can clarify this relationship. Such an undertaking would require both tenacious and rigorous scholarship that would seek to understand both the underlying values of beauty related social media that appeal to users and the preferences of certain beauty related social media. In doing so, this undertaking must also integrate a measure of overall health to gauge a better understanding of this relationship on a more nuanced level. Second, in addition to the relationship on enjoyment of beauty related social media and self-esteem, support for intention to participate in beauty-related social media was found. As a cursory exploration, these findings offer several new questions for additional scholarship. First, if self-esteem is impacted by use of social media sites, then what is the impetus for participation? Second, what role do the content creators play in the shaping of beauty ideals?

Several limitations are notable in the current study. First, an online survey was conducted based on convenience sampling, with data from a university sample. This offered both beneficial and negative benefits. For instance, as an initial exploration, this sampling was necessary, as one of the biggest consumers of beauty-related social media content are college students (Statista, 2014). However, while this was a key first step for this research, future research attempts need to strive for more generalizable populations. In addition, the measurement selected as an initial method of approach, to measure TPB variables in a way that closely matched Ajzen's (1991) recommendations, which have long been tested as valid and reliable assessments. Additional measures may be used to seek out other means of capturing data-for instance, Wright \& Hinson (2010) measured attitudes towards social media by ranking them based on importance. This scale may be useful in a study of beauty-related social media use where the technology itself is a central factor. 
An important avenue for future research will necessitate direct interviews with the curators of popular social media content about how communication facilitates their self-presentation and their perceived impact on others. As Walther (1996) proposed in the Hyperpersonal model, users carefully engage in self-presentation, where they generally do not transmit undesirable behaviors. Instead, they tend to construct messages that encourage communication in positive ways, and encourage preferential reactions to their behaviors. For instance, individuals who receive sponsorship from beauty companies on social media have leverage in reaching a wide audience and having greater communication to receivers (Walther, 1996), which are more limited. They are senders of messages, receivers, participants and selectors in the channel, and in delivering feedback - while the receivers may have limits in their ability to communicate with popular sponsors. The relationship between sender and receiver in this context provides an avenue for future scholarship in this domain, particularly since the notion behind the use of everyday individuals in selling products is to use relatable figures as opposed to celebrity figures (Morry \& Statska, 2001). While content creators are able to sufficiently control their content, the receivers of the content are limited in that they are the recipients of content.

The current study provides early insight on self-presentation of beauty-related social media use through an examination of the Hyperpersonal model and the Theory of Planned Behavior. Examining overt communication behaviors (e.g., sharing photos of using products, forming friendships through consumer pages, etcetera) and self-esteem will provide additional insight about the nature of longitudinal use of these contents. As social media sites are at the forefront of human communication and technology research (Moradi \& Huang, 2008; Walther \& Jang, 2012), the relatively small impact that content may have may play an important role on self-identity, esteem, and one's overall self.

\section{Acknowledgements}

We are grateful for all participants who took the time to participate in this study.

\section{References}

Adams, G. R., \& Huston, T. L. (1975). Social perception of middle-aged persons varying in physical attractiveness. Developmental Psychology, 11, 657-688. http://dx.doi.org/10.1037/0012-1649.11.5.657

Ajzen, I. (1991). The theory of planned behavior. Organizational behavior and human decision processes, 50 (2), 179-211. http://dx.doi.org/10.1016/0749-5978(91)90020-T

Ajzen, I., \& Sheikh, S. (2013). Action versus inaction: Anticipated affect in the theory of planned behavior. Journal of Applied Social Psychology, 43 (1), 155-162. http://dx.doi.org/10.1111/j.1559-1816.2012.00989.x

Aubrey, J. S. (2006). Effects of sexually objectifying media on self-objectification and body surveillance in undergraduates: Results of two-year panel study. Journal of Communication, 56, 1-21. http://dx.doi.org/10.1111/j.1460-2466.2006.00024.x

Back, M. D., Stopfer, J. M., Vazire, S., Gaddis, S., Schmukle, S. C., \& Egloff, B. (2010). Facebook profiles reflect actual $\begin{array}{lllll}\text { personality, not } \quad \text { self-idealization. } & \text { Psychological } & \text { Science, } & \text { 21(3), }\end{array}$ http://dx.doi.org/10.1177/0956797609360756

Britt, R. K., \& Hatten, K. N. (2013). Need for cognition and electronic health literacy and subsquent information seeking behaviors among university undergraduate students. Sage Open, 3, 1-10. http://dx.doi.org/10.1177/2158244013508957

Burke, K. (1959). Attitudes toward history. Berkeley, CA: University of California Press.

Byrne, B. M. (1996). Measuring self-concept across the life span: Issues and instrumentation. Washington, DC: American Psychological Association. http://dx.doi.org/10.1037/10197-000

Cooper, A. L. (2004). The inmates are running the asylum: Why high tech products drive us crazy and how to restore the sanity. Copenhagen: Sams Publishing.

de Vries, L., Gensler, S., \& Leeflang, P. S. H. (2012). Popularity of brand posts on brand fan pages: An investigation of the effects of social media marketing. Journal of InteractiveMarketing, $26, \quad 83-91$. http://dx.doi.org/10.1016/j.intmar.2012.01.003

Dillard, J. P., \& Spear, M. E. (2010). Knowledge of human papillomavirus and perceived barrios to vaccination in a sample of US female college students. Journal of American College Health, 59 (3), 186-190. http://dx.doi.org/10.1080/07448481.2010.493189

Dittmar, H. (2009). How do "body perfect" ideals in the media have a negative impact on bodyimage and behaviors? Factors and processes related to self and identity. Journal ofSocial and Clinical Psychology, 28, 1-8.

Duthler, K. W. (2006). The politeness of requests made via email and voicemail: Support for the hyperpersonal model. Journal of Computer-Mediated Communication, 11, 500-521. http://dx.doi.org/10.1111/j.1083-6101.2006.00024.x 
Ellison, N., Heino, R., \& Gibbs, J. (2006). Managing impressions online: Self-presentation processes in the online dating environment. Journal of Computer-Mediated Communication, $11, \quad 415-441$. http://dx.doi.org/10.1111/j.1083-6101.2006.00020.x

Fishbein, M., \& Ajzen, I. (1975). Belief, attitude, intention, and behavior: An introduction to theory and research. Reading, MA: Addison-Wesley.

Fishbein, M., \& Ajzen, I. (2010). Predicting and changing behavior: The reasoned action approach. New York: Psychology Press.

Fowler, B. (2014a). JuicyStar07's Channel- YouTube. http://www.youtube.com/user/juicystar07

Fowler, E. (2014b). All that Glitters' Channel- YouTube. http://www.youtube.com/user/AllThatGlitters21

Fredrickson, B. L., \& Roberts, T. A. (1997). Objectification theory: Toward understanding women's lived experiences and mental health risks. Psychology of Women Quarterly, 21, 173-206. http://dx.doi.org/10.1111/j.1471-6402.1997.tb00108.x

Fujioka, Y., Ryan, E., Agle, M., Legaspi, M., \& Toohey, R. (2009). The role of racialidentity in responses to thin media ideals: Differences between white and black collegewomen. Communication Research, 36, 451-474. http://dx.doi.org/10.1177/0093650209333031

Goffman, E. (1959). The presentation of self in everyday life. New York: Anchor Books.

Goldsmith, D. J. (2004). Communicating social support. New York, NY: Cambridge University Press. http://dx.doi.org/10.1017/CBO9780511606984

Gosling, S. D., Gaddis, S., \& Vazire, S. (2007). Personality impressions based on Facebook profiles. Proceedings of the ICWSM, Boulder, CO. http://www.icwsm.org/papers/3--Gosling-Gaddis-Vazire.pdf

Grabe, S., \& Hyde, J. S. (2009). Body objectification, MTV, and psychological outcomes among female adolescents. Journal of Applied Social Psychology, 39, 2840-2858. http://dx.doi.org/10.1111/j.1559-1816.2009.00552.x

Graham, J. A., \& Kligman, A. M. (1984). Cosmetic therapy for the elderly. Journal of the Society of Cosmetic Cosmetics, 35, 133-145. http://dx.doi.org/10.1057/bm.2008.28

Graham, J. A., \& Kligman, A. M. (1985). Physical attractiveness, cosmetic use and self-perception in the elderly. International Journal of Cosmetic Science, 7, 85-97.

Guthrie, M. F., \& Kim, H. (2009). The relationship between consumer involvement and brand perceptions of female cosmetic consumers. Journal of Brand Management, 17, 114-133. http://dx.doi.org/10.1057/bm.2008.28

Hancock, J. T., \& Toma, C. (2009). Putting your best face forward: The accuracy of online dating photographs. Journal of Communication, 59, 367-386.

Hayes, A. F. (2009). Beyond Baron and Kenny: Statistical mediation analysis in the new millennium. Communication Monographs, 76 (4), 408-420.

Herek, G. M. (2000). The social construction of attitudes: Functional consensus and functional divergence in the U.S. public's reaction to AIDS. G. R. Maio \& J. M. Olson (Eds.), Why we evaluate: Functions of attitudes. Mahwah, NJ: Lawrence Erlbaum Associates, Inc.

Jacob, C., Guéguen, N., Boulbry, G., \& Ardiccioni, R. (2010). Waitresses' facial cosmetics and tipping: A field experiment. International Journal of Hospitality Management, 29, $188-190$. http://dx.doi.org/10.1016/j.ijhm.2009.04.003

Jawahar, J. V., \& Tamizhjyoti, K. (2013). Consumer attitudes towards cosmetic products. International Journal of Exclusive Management Research, 3, 1-7.

Jiang, L. C., Bazarova, N. N., \& Hancock, J. T. (2011). The disclosure-intimacy link in computer-mediated communication: An attributional extension of the hyperpersonal model. Human Communication Research, 37 , 58-77.

Jones, E. E., \& Pittman, T. S. (1982). Toward a general theory of strategies self-presentation. Psychological perspectives on the self, 1, 231-262. Hillsdale, NJ: Erlbaum.

Kahn, A. S., Ratan, R., \& Willias, D. (2014). Why we distort in self-report: Predictors of self-report errors in video game play. Journal of Computer-Mediated Communication, article ahead of print. http://dx.doi.org/10.1111/jcc4.12056

Katz, J. E., \& Rice, R. E. (2002). Social consequences of Internet use: Access, involvement, and interaction. Cambridge: MIT Press. 
Kharim, H. S. (2011). The influence of brand loyalty on cosmetics buying behavior of UAE female consumers. International Journal of Marketing Studies, 3, 123-133.

Kim, H., \& Davis, K. (2009). Toward a comprehensive theory of problematic Internet use: Evaluating the role of self-esteem, anxiety, flow, and the self-rated importance of Internet activities. Computers in Human Behavior, 25, 490-500.

Kim, M., Kwon, K., \& Lee, M. (2009). Psychological characteristics of Internet dating service users: The effect of self-esteem, involvement, and sociability on the use of Internet dating services. Cyberpsychology, behavior and social networking, 12, 445-449.

Krasnova, H., Spiekermann, S., Koroleva, K., \& Hildebrand, T. (2010). Online social networks: Why we disclose. Journal of Information Technology, 25, 109-125.

Lea, M., \& Spears, R. (1995). Love at first byte? Building personal relationships over computer networks. J. T. Wood \& S. Duck (Eds.), Under-studied relationships: Off the beaten track (pp.197-233). Thousand Oaks: Sage Publications.

Leary, M. R., \& Kowalski, R. M. (1990). Impression management: A literature review and two-component model. Psychological Bulletin, 107(1), 34-47.

Leary, M. R., Tambor, E. S., Terdal, S. K., \& Downs, D. L. (1995). Self-esteem as an interpersonal monitor: The sociometer hypothesis. Journal of Personality Psychology, 68, 518-530.

Leary, M. R., Terry, M. L., Allen, A. B., \& Tate, E. B. (2009). The concept of ego threat in social and personality psychology: Is ego threat a viable scientific construct? Personality and Social Psychology Review, 13, 151-164.

Moradi, B. (2010). Addressing gender and cultural diversity in body image: Objectification theory as a framework for integrating theories and grounding research. Sex Roles, 63, 138-148. http://dx.doi.org/10.1007/s11199-010-9824-0

Moradi, B., \& Huang, Y. (2008). Objectification theory and psychology of women: A decade of advances and future directions. Psychology of Women Quarterly, 32, 377-398. http://dx.doi.org/10.1111/j.1471-6402.2008.00452.x

Morry, M. M., \& Statska, S. L. (2001). Magazine exposure: Internalization, self-objectification, eating attitudes, and body satisfaction in male and female university students. Canadian Journal of Behavioral Science, 33, 269-279. http://dx.doi.org/10.1037/h0087148

O'Reilly, T. (2007). Web 2.0: Compact definition? O'Reilly Radar. http:// radar.oreilly.com/archives/2005/10/web-20-compact-definition.html

Papacharissi, Z. (2002). The presentation of self in virtual life: Characteristics of personal home pages. Journalism and Mass Communication Quarterly, 79(3), 643-661. http://dx.doi.org/10.1177/107769900207900307

Parker, E. (2002). Ladies Home Journal: A content analysis of the marriage advice given in Ladies HomeJournal from the 1950s and 1990s. Paper presented at the AEJMC Conference, Florida.

Pew Internet \& American Life Project (2014). Pew Research Center's Internet \& American Life Project. http://www.pewinternet.org

Pontari, B. A., \& Schlenker, B. R. (2006). Helping friends manage impressions: We like helpful liars but respect nonhelpful truth tellers. Basic and Applied Social Psychology, 28, 177-183. http://dx.doi.org/10.1207/s15324834basp2802_7

Regan, P. C. (2011). Cinderella revisited: Women's appearance modification as a function of target audience sex and attractiveness. Social Behavior \& Personality: An International Journal, 39, 563-576.

Rosenberg, M. (1965). Society and the adolescent self-image. Princeton, NJ: Princeton University Press.

Schiffrin, H., Edelman, A., Falkenstern, M., \& Stewart, C. (2010). The associations among computer-mediated communication, relationships, and well-being. Cyberpsychology, Behavior, and Social Networking, 13, 299-306. http://dx.doi.org/10.1089/cyber.2009.0173

Smith, C. B. (1997). Casting the net: Surveying an Internet population. Journal of Computer-Mediated Communication, 3. http://dx.doi.org/10.1111/j.1083-6101.1997.tb00064.x

Sparks, P., \& Guthrie, C. A. (1998). Self-identity and the theory of planned behavior: A useful addition or an unhelpful artifice? Journal of Applied Social Psychology, 28, 1393-1410.

Sproull, L., \& Kiesler, S. (1991). Connections: New ways of working in networked organization. Cambridge, MA: MIT Press. 
Statista. (2014). Beauty Online: Brands on http://www.statista.com/study/20948/beauty-brands-on-youtube/

Steinfield, C., Ellison, N., \& Lampe, C. (2008). Social capital, self-esteem, and the use of online social network sites: A longitudinal analysis. Journal of Applied Developmental Psychology, 29, 434-445. http://dx.doi.org/10.1016/j.appdev.2008.07.002

Thorbjornsen, H., Pedersen, P. E., \& Nysveen, H. (2007). "This is who I am": Identity expres siveness and the theory of planned behavior. Psychology \& Marketing, 24(9), 763-785. http://dx.doi.org/10.1002/mar.20183

Tiggemann, M. (2010). Mental health risks of self-objectification: A review of the empirical evidence for disordered eating, depressed mood and sexual dysfunction. In R. M. Calogero, S. Tantlfeff-Dunn, \& J. K. Thompson (Eds.), Self-Objectification in women. Causes, consequences and counteractions (pp.139-160). Washington, D.C.: APA.

Toma, C. L. (2013). Feeling better but doing worse: Effects of Facebook self-presentation on implicit self-esteem and cognitive task performance. Media Psychology, 16, 199-220. http://dx.doi.org/10.1080/15213269.2012.762189

Toma, C. L., \& Carlson, C. L. (2015). How do Facebook users believe they come across in their profiles? A meta-perception approach to investigating Facebook self-presentation. Communication Research Reports, 32(1), 93-101. http://dx.doi.org/10.1080/08824096.2014.990557

Valkenburg, P. M., Jochen, P., \& Schouten, A. P. (2006). Friend networking sites and their relationship to adolescents' well-being and social self-esteem. Cyberpsychology and Behavior, 9(5), 584-590. http://dx.doi.org/10.1089/cpb.2006.9.584

Vandenbosch, L., \& Eggermont, S. (2012). Understanding sexual objectification: A comprehensive approach toward media exposure and girls' internalization of beautyideals, self-objectification, and body surveillance. Journal of Communication, 62, 869-887. http://dx.doi.org/10.1111/j.1460-2466.2012.01667.x

VidStats (2014). YouTube top 100 most subscribed channels list http://vidstatsx.com/youtube-top-100-most-subscribed-channels

Walther, J. B. (1996). Computer-mediated communication: Impersonal, interpersonal, and hyperpersonal interaction. Communication Research, 23, 3-43. http://dx.doi.org/10.1177/009365096023001001

Walther, J. B., \& Jang, J. (2012). Communication processes in participatory websites. Journal of Computer-Mediated Communication, 18, 2-15. http://dx.doi.org/10.1111/j.1083-6101.2012.01592.x

Walther, J. B., \& Parks, M. (2002). Cues filtered out, cues filtered in: CMC and relationships. M. Knapp \& J. Daly (Eds.), Handbook of Interpersonal Communicatoin, 529-563. Thousand Oaks: Sage.

Wang, X. (2009). Integrating the theory of planned behavior and attitude functions: Implications for health campaign design. Health Communication, 24, 426-434. http://dx.doi.org/10.1080/10410230903023477

Wilcox, K., \& Stephen, A. T. (2013). Are close friends the enemy? Online social networks, self-esteem, and self-control. Journal of Consumer Research, 40, S63-S76.

Yzer, M. (2007). Does perceived behavioral control moderate attitudinal and normative effects on intention? Prediction and change of health behavior: Applying the reasoned action approach (pp. 107-123). Mahwah, NJ: Lawrence Erlbaum.

\section{$(\mathrm{cc}) \mathrm{BY}$}

This work is licensed under a Creative Commons Attribution 3.0 License. 